\title{
A Wary Alliance: \\ From Enumerating the Environment to Inviting Apprehension
}

\author{
NichOLAS SHAPIRO ${ }^{1}$ \\ ChEMicAl Heritage Foundation \\ NASSER ZAKARIYA \\ UNIVERSITY OF CALIFORNIA, BERKELEY \\ JODY A. ROBERTS \\ CHEMiCAl Heritage Foundation
}

\begin{abstract}
In this paper we resituate discussions of community-based science beyond the emancipatory rhetoric of democratization, creative commons, and the blurring of the bulwarks of expertise to include consideration of the potentially constrictive instrumentalist scientific idiom produced by and through these practices. Collectively, we apply four interrelated insights already available within STS literature to the chemical ecologies that we are immersed within and perpetuate: 1) projects engaged in the use of science for justice claims cannot fully escape reproducing hierarchies of knowledge-power, type, and knower; 2) the pursuit of science in these instances has the potential to foreclose imaginative horizons of "how" and "why" in favor of "how much"; 3) the pursuit of more data sets the stage for adversarial epistemological encounters that can lead to entrenchment rather than resolution; and 4) these practices have the resultant effect of defining and confining (democratic) participation to one in which data become an essential gateway to having a voice. Following from this, we ask: what are the approaches to apprehending the environment that might not so easily boil down to binaries of benevolence or harm, or to renderings of uncertainty confined to the specifications of statistical confidence intervals, that in turn justify further scientific inquiry? We gesture towards an expansive conversation that we call
\end{abstract}

\footnotetext{
1 Nicholas Shapiro, Email: nshapiro@chemheritage.org

Copyright (C) 2017 (Nicholas Shapiro, Jody Roberts, and Nasser Zakariya). Licensed under the Creative Commons Attribution Non-commercial No Derivatives (by-nc-nd). Available at estsjournal.org.
} 
"inviting apprehension." Such approaches beckon multiple strata of apprehending the environment to provoke public inquiry and intervention into the questions that undergird what we assume are the problems of today and the avenues through which we must engage them.

\section{Keywords}

environment; monitoring; data; creative practice; methods

\section{Introduction}

The eerie, lumbering chords of the Call of Duty soundtrack, looping on the TV, suffused the air with an added texture of unease. I (Nick) leaned over to the window, rolling the colorimetric tube back and forth between my fingers, trying to discern the length of discoloration in the formaldehyde detection tube. The material in the tube changes from yellow to pink as it encounters formaldehyde, producing a length-of-stain reading like a pastel thermometer.

"Hopefully the results are not worrisome," said Joe in a controlled yet expectant manner, one that wavered on the last word and pivoted his statement into a tentative question. Reading, and then temperature correcting, the tube I responded slowly, "It is not too bad.... but they are not.....ya know... incredible. They are about 20 parts per billion. Which is..."

"What's the danger zone?" Joe, an increasingly red-faced 24-year-old trailer resident whose indoor air quality was under scrutiny, interjected, "can you put it into perspective for me?"

"Yeah, of course," I reassured before joking, "It's 20! There you go. Bye," and feigned walking out the door, satirizing the extractive data collection practices that community science aims to overcome. We both laughed nervously, but for different reasons. I began to tie lines of relation between his home and his reading to readings in other homes: "This level is five times better than this same model of trailer four years ago, but it is double a 'normal' home.... It is more than double the non-cancer federal guaranteed safe level for a year of inhalation, but that doesn't mean they found levels at 9 or $10 \mathrm{ppb}$ to be harmful, the state applied precautionary factors... [and on and on]." As we spoke it became increasingly clear that Joe's home atmosphere occupied a scientific no-man's land. All of these relational perspectives cast from governmental guidelines, from monitoring homes, from modeling cancer risk, all fell short of solidifying the meaning of this number that had been plucked from his air. His level bore some proximity to "average" domestic air quality, but still maintained a distance from the safety-in-numbers comfort of a 
"normal" exposure. Twenty parts per billion is more than double the federal minimum response level and the EPA 1 in 10,000 cancer risk level, levels below which mitigation is generally understood as unnecessary, but much lower than the levels I normally found in the homes of people with acute effects from formaldehyde, of which he felt none. ${ }^{2}$

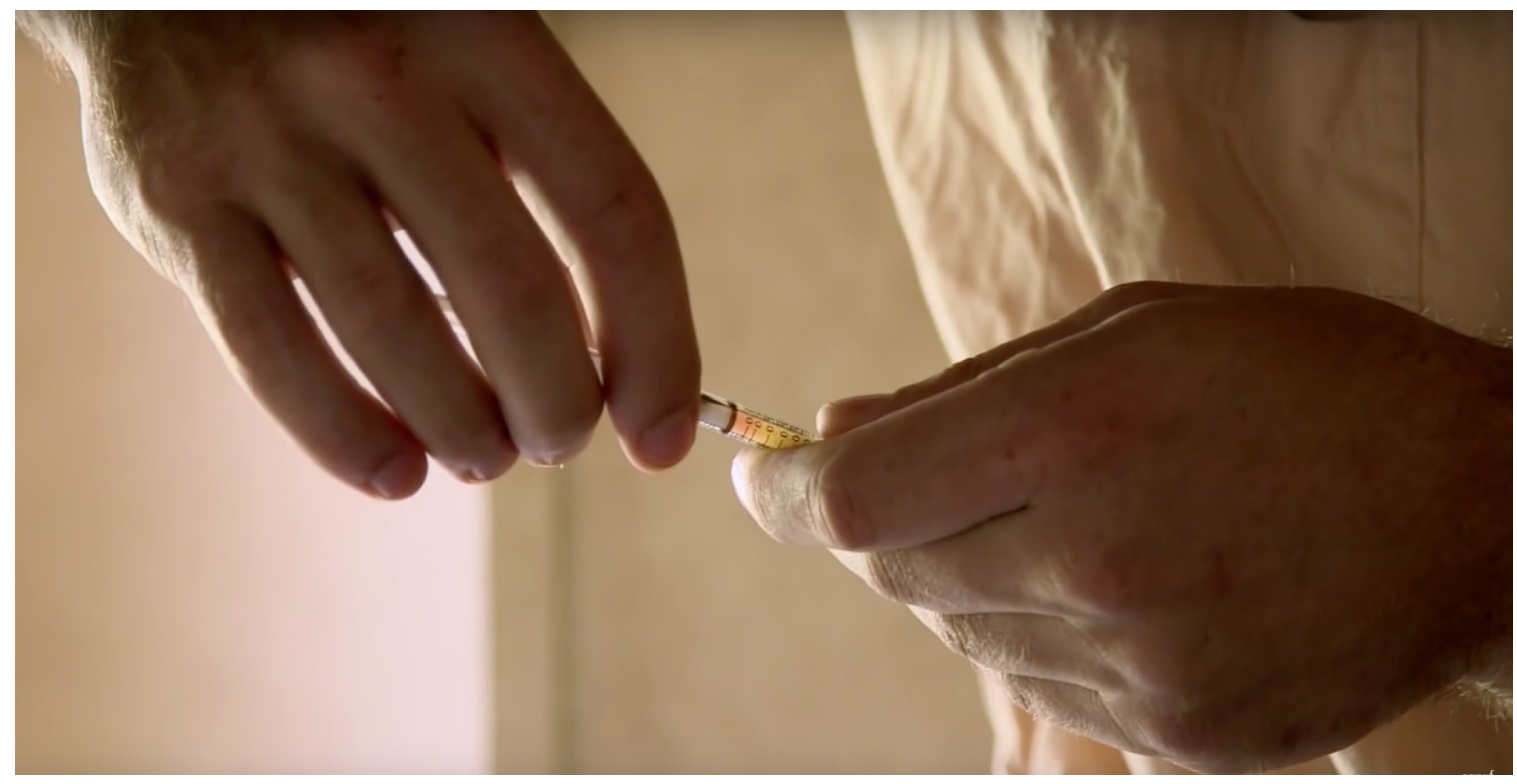

Image 1: Holding the formaldehyde tube in Joe's home. Pink discoloration signals formaldehyde concentration. Photo: Mariel Carr.

As we charted the fractured landscape of toxicological, epidemiological, and regulatory guidelines, Joe came to recognize that adverse health effects were possible, but not exceedingly probable. ${ }^{3}$ As we talked he became more and more comfortable inhabiting a grey zone of chemical exposure-as his levels were not alarming even if they were not unequivocally "safe." But while Joe became more comfortable, I was becoming increasingly uncomfortable with what I was reproducing. My initial joke, distancing myself from conventional scientific practice, was

\footnotetext{
${ }^{2}$ Selections from these moments can be viewed online in a mini-documentary for Distillations Magazine and Grist: “Where Have all the FEMA Trailers gone?" Directed by Mariel Carr https:/ / vimeo.com/137439033.

${ }^{3}$ This is in line with Brody et al.'s finding that reporting uncertain toxicant monitoring data back to the individuals whose exposures are being studied does not create excessive worry or anxiety. The authors did, however, note that the process is "intellectually challenging, time consuming, and [made researchers] concerned that it required skills beyond their expertise" (Brody et al. 2014: 6). See also Roberts (2014).
} 
giving way to the suspicion that my research was not as distinct from the knowledge-power orthodoxy as I would like to think, even if the research instruments and study design were intended to challenge that culture: highly inexpensive, openly-licensed instruments in pursuit of a research agenda driven explicitly by concerns of the disproportionately exposed rural poor. While I was troubling how to ask a question, I was also thereby reassuring it was indeed the right question to be asking.

Pull back from the close-up of the formaldehyde tube and the anticipation of whether or not its results are worrisome and you will see that Joe's home is one of 120,000 former emergency housing units that FEMA (the US Federal Emergency Management Agency) had built for those displaced by Hurricanes Katrina and Rita in 2005. These bare-bones homes became internationally infamous for harboring elevated indoor formaldehyde concentrations. Zoom out further still and you will see that his trailer is one of thousands of identical units that wound their way through quasi-legal economies and landed on the Bakken shale field in rural North Dakota. Pan over to the oil and gas well pads a half-mile from Joe's trailer to find the extraction of methane, from which formaldehyde is derived. Oilmen had streamed into rural boomtowns to land hydrocarbon extraction jobs, sending rents skyrocketing. Rural towns experienced rents higher than those of Manhattan. What was supposed to be a summer job for Joe in the hospitality industry - where oil profits inflated wages—turned into a multi-year stint after a DUI saddled him with a sizable debt. Cutting down debt or building up a nest egg were the only two justifications I heard for subjecting oneself to the Bakken.

If we do resist the stock dramas of science and technology, the promises of empowerment and of making the invisible visible as data points, we can see beyond the individual toxicity or lack thereof to understand the widespread patterns, cultural forms, building practices, and commodity pathways that purvey harms well beyond the molecular register. In this light we can see micro-toxicities as indexical of their macro-toxicities; Joe's home can be seen as the crystallization of the legacies of epochal disasters, extractive economies, promises of fortune that yield debt, multiple shades of the housing crisis, and the molecular trajectories of formaldehyde that returned to the site of its geological extraction. All of these intricately entangled infrastructures and phenomena reveal multiple hows and whys of exposure, yet are eclipsed by the questions raised by the analytical chemistry and whether or not the measurement by the detection tube, the enumeration, was within a "danger zone."4

${ }^{4}$ Despite being based on a peer-reviewed method, this technique was later found to be potentially overestimating formaldehyde levels due to crossreactivity with other aldehydes and ketones (Gehrke and Shapiro 2015). 
A discrete formaldehyde concentration routed both Joe and me into a search for the perpetually out of reach threshold of tolerability-a boundary at which his home atmosphere transforms from bearable to dangerous. Even if this threshold could be numerically pinpointed, what is Joe to do armed with that number as he looks out at the unflinchingly flat horizon punctuated only by oil wells and trailers? As he checks his bank account on his phone? As he looks at other comparable places to live that cost a thousand dollars more per month? Joe's quandary is ultimately not just the individualist dilemma of how to navigate uncertainty. The very pursuit of finding buoyancy and meaning among indeterminate data resists bigger/ ancillary/other questions becoming askable. Even if Joe were to feel his atmosphere intolerable and found someplace else to live, his trailer would be re-occupied in a matter of hours. Just one hundred feet away, five men share an identical 150 sq foot FEMA trailer and collectively pay $\$ 1,200$ more per month than Joe, who lives on his own. How much of what is shared in their situations is addressed by the enumerations measurements provide, and how much is bracketed? Beyond routing us towards unanswerable questions, quantifying and contextualizing a potential toxicity also works to direct us towards straightforward, but potentially superficial, solutions.

How can the gravity of human molecular harm serve as an opportunity to make sense of the infrastructures, logics of capitalism, regimes of perception, and industrial practices that manifest and maintain the possibility of formaldehyde toxicity in all of our lives and thus better render a way out? These questions do not abandon Joe and his concerns but evince how removing him from the trailer (the putative outcome of a definitive assessment of toxicity) would mitigate one exposure while maintaining other shared exposures-exposures of the market, debt, brutal winters, fugitive endocrine disrupters from nearby wellheads, ${ }^{5}$ etc. Stepping out of the frame of risk distillation as an enumerative practice provides a better picture of what the impossible prize of the certitude of absolute monitoring could not accomplish and calls attention to the fact that prevention of such exposures require interventions beyond the mere engineering of the home.

The reflections that grew into this article began with a conversation between the authors a couple months prior to being in Joe's trailer in which one of us (Jody) wondered out loud whether those who practice citizen science in relation to toxic environmental exposures are the people that potentially have the most to lose when the transformative promises of science do not pan out. Not only does enumerating the environment tend to maintain a certain hegemony about

5 "You smell that sweet smell?" Joe asked Nick when they were standing outside waiting for the test to finish, "that's from a [oil] flare." The endocrine disrupters benzene and toluene may be components of that smell. 
which questions are available for the asking, but can lead to a situation in which those with the fewest resources and the highest exposure have the greatest investment in sciences that are relatively ineffective, or "powerless," (Boudia \& Jas 2014) on their own to rectify the problems that they seek to elucidate. These questions took further root as one of us (Nasser) situated these concerns within a longer historical trajectory, substantiating and questioning the scientization of society and its concomitant effects on democracy in practice. 6

In uniting our own research trajectories and agendas, we came to focus on four interconnected reasons for caution in deploying enumerative practices in pursuit of environmental and health justice: 1) projects engaged in the use of science for justice claims cannot fully escape reproducing hierarchies of knowledge-power, type, and knower; 2) the pursuit of science in these instances has the potential to foreclose imaginative horizons of "how" and "why" in favor of "how much"; 3) the pursuit of more data sets the stage for adversarial epistemological encounters that can lead to entrenchment rather than resolution; and 4) these practices have the resultant effect of defining and confining (democratic) participation to one in which data become an essential gateway to having a voice. These are not unique insights to the three of us, but rather the collective resulting work of our and other communities' probing analysis of the place of science in their societies. While some of these specific issues are taken up more specifically in what follows, our goal in this paper is to build from these insights so that we can begin to articulate an approach towards a more expansive toolkit of interventionist practices.

While Nick's practice, as indicative of a larger rise in "civic technoscientific" practice within STS (Wylie et al. 2014), may move to expand those invited to sit at the table of science and what tools can be wielded in the name of technocratic reform, we also must pay close attention to the ceilings in capacity, community-building, imagination, and efficacy when tendering and transacting in scientific data. By foregrounding what we call the "politics of enumeration," we situate community science here not just within the emancipatory rhetoric of democratization, creative commons, and the blurring of the bulwarks of expertise, but also within a potentially constrictive instrumentalist scientific idiom. Many of the civic environmental monitoring projects that have been most successful by their own standards have been those not leveraging numerical data but curating and testifying in images of oil soaked marshlands, effluent discharge in urban waterways, dead flora from an aerial perspective as evidence of subterranean toxicant perfusion, or gas rig workers not wearing required protections. The aforementioned four reasons for seeking

6 The starting point for our joint conversations was the Chemical Heritage Foundation Matters and Materials Research Group, convened by Jody. 
alternatives to enumerating ecological threats certainly hang more loosely on these extranumerical evidentiary projects, perhaps precisely because they exceed the scope of data sciences.

This introduction is not a mea culpa on Nick's behalf that seeks to cast a sinister light upon the work pursued by practitioners of community science. The self-reflexive critique of the first half of this article is an inroads into the more affirmative philosophy of this paper, which attempts to say "yes, and" (or perhaps more specifically, "yes, but first") to civic science, and point to efforts that may make our publicly engaged work better able to give rise to possibilities of living otherwise, or at least to orientations towards more capacious otherwises. In the second half of this article, we both theorize and take preliminary steps towards empirically substantiating an approach that we call "inviting apprehension." These reflections on method are offered as outlines for further elaboration and not a prescription for how work must be done. Our intention is to shift the conversation and leave it open; not to critique it and treat it as settled.

We work from the observation that "toxicity" often functions as a proxy for a range of cultural, economic, or infrastructural instabilities that are, indeed, something "toxic" but are far more complicated and difficult to identify. Perhaps more consequentially, focus on discrete "toxic" elements of a material or system reifies the fantasy that we can escape from specific materials to achieve a salutogenic world rather than pointing to the necessary deeper engagement that is required to reinvent the materials of our everyday life (Roberts 2010). So a core question to us seems to be: How do we sustain a more trenchant examination not only of the thick constructions of and surrounding toxicity, but also of what specific deployments of "toxic" can work to silence?

To summarize, our inquiry here is two-part. How, we wonder, do enumerative engagements with the environment delimit how we conceive of the chemical ecologies that we are immersed within and perpetuate? Following that, what are the approaches to apprehending the environment that might not so easily boil down to binaries of benevolence or harm, or to renderings of uncertainty confined to the specifications of statistical confidence intervals, that in turn justify further scientific inquiry? To route around these shortcomings that reduce the capacity for substantive reflection and/or intervention, we look to patterns of work already at play, approaches "inviting apprehension," beckoning multiple strata of apprehending the environment to provoke public, often (but not only, or necessarily) participatory, inquiry and intervention into the questions that undergird what we assume are the problems of today and the avenues through which we must engage them. 


\section{Science for Justice, and Critiques}

Enumerative projects bear unimaginably diverse manifestations, from technological standardization and innovation and measurements of labor time and productivity, to state surveying, mapping, and concomitant planning, and population demographics, health, and governance. ${ }^{7}$ Even in a cursory view, such calculative initiatives present a thicket of precedents that inform current practices of environmental monitoring, whether couched in terms of citizen science, community science, civic science, or state science. In short, enumerative practices have been so culturally pervasive and extensive as to threaten to make any historical analysis of them an exercise in the assessment of modernity.

Long before a ubiquitous social trust in numbers, their broad use elucidated and made visible social values and accountability. In Mary Poovey's (1998) telling of the transfer and evolution of practices of accounting in early Modern Europe, enumerative technologies (not numbers alone) neatly fold the physical, social, and political worlds into a single calculative practice. Numeric outcomes become the obligatory terrain upon which knowledge of and about a people or place must be contested. These practices of trade and commerce quickly found themselves applied to transfers of land and peoples as well as goods, becoming a key tool in the production and maintenance of sovereign and colonial power. These histories suggest the need to examine the degree to which the use and exercise of the tools of technoscience can be extracted from their dual role in the maintenance of power as inextricable from the maintenance of life (Foucault 2003, 2009).

Past critically-minded theorists-whether natural or social scientists, philosophers, novelists, or artists--have wrestled with the impact of scientific enumerative practices on their own critical perspectives and assessments. The abundance of these reflections underscores the fact that the drive to "democratize" science in order to empower the citizen(ry) can surrender a critical perspective on the state, economy, and science to the rubrics by which they know and substantiate themselves. Even so, it remains difficult to imagine a future that must wrestle with the possible impermanence, impotence, or harmfulness of either official governance or formalized sciences. As is the case with civic science, the spaces we are left for critical reflection

\footnotetext{
${ }^{7}$ Among wide-ranging histories of race, eugenics, and population controls to those of state formation and colonization, we might include: Hacking 1990; Stocking 1994; Porter 1996; Scott 1998; Paul 1998; Mitchell 2002.
} 
tend to constrain intellectual endeavor to deliberating over the relationship between science and governance, rather than questioning the institutions themselves. ${ }^{8}$

Already by the mid-nineteenth century, mathematician and astronomer John Herschel averred that science-and "no other quarter"-would satisfy the pressing material demands of human life. A century later, social scientists such as Otto Neurath in Austria and natural scientists such as J.D. Bernal in England continued to insist that scientific knowledge and its universalization is the key to solving social problems. In looking to science to address social inequity, which Bernal saw as the core obstacle to more general improvements, he declared the need for a citizenry that knows and understands modern science "possibly better than the scientists themselves" (Bernal 1945: 476). Bernal's dream citizen takes the form of scientific auditor, keeping science on its rails, through critiques internal to its logic. This rendering of civic engagement is uncannily similar to a dominant imagined role of citizen science today, yet the present-day citizen scientist is tasked with keeping not just science on even keel but also government and industry. This model of active citizenship, which holds the enumerative powers of science as the key to collective betterment, precedes the rise of self-conscious neoliberal policy and the oft-cited free-labor justification for and critique of citizen science ( $c f$ Kinchy et al. 2014).

\section{Data Treadmill}

Critiques of scientific enumerations of social worlds could be found broadcast in the "untimely" meditations of Nietzsche or in Dostoyevksy's Notes from Underground, each in their way challenging the promises that contemporary scientific theory held for the possibility of human flourishing. Likewise, the continued wariness of enumeration (understood both narrowly as discourse tending to numeric scientific verdicts, and as a figure for naturalizing scientific

\footnotetext{
8 Social theorist Max Horkheimer argued that positivist and logical empiricist agendas constricted political emancipatory possibilities, addressing social problems only in narrow and non-transformational terms. In his view, the "mere recording and prediction of facts," inspired resignation and impotence in relation to "vital issues" while also rarifying the capacity to intervene in such systems to an exclusive powerful few who arbitrate the facts that matter, working to sustain a status quo. The goal, to his mind, was a "higher spontaneity" wherein thought is not restricted to examining apparently unalterable circumstances by the lights of "feeble and abstract" calculative thought alone but instead can ultimately be traced to their social and political supports-circumstances that might therefore be reconceived and reimagined. As a "prerequisite" for the achievement of a better community an individual must "learn to look behind the facts; that he distinguish the superficial from the essential without minimizing the importance of either; that he formulate conceptions that are not simple classifications of the given; and that he continually orient all his experiences to definite goals without falsifying them [...]" (Horkheimer 1972: 181).
} 
determination more generally) played a role in debates thereafter on the question of scientific instrumentalism. ${ }^{9}$

Despite the diversity and voracity of these critiques, socially- or politically-engaged enumerative processes have continued largely unabated. Indeed, one might argue that we are ever more self-consciously enmeshed in a scientized world and an enumerated environment. Data defines, and repeatedly and multiply redefines, our landscapes, communities, and bodies. Our regulations, laws, critiques, and conversations depend upon that data. And yet, as Boudia and Jas (2014) provocatively question: are we placing all of our hopes-for justice, for sustainability, for flourishing-on a "powerless science?" Infrastructure invested in these regulatory and research activities only grows more extensive in scope and sophistication. And yet, for all of this effort, toxicants and their effects on environments and landscapes can never be enumerated enough — eternally requiring further verification and precluding more expansive lines of inquiry. ${ }^{10}$ In this way, the restrictive modes of problem-setting in environmental enumeration are entwined with a shortcoming of feasibility, of delivering on its own terms. Such a combination yields confined dreams that are impossible to attain. From plastics (Vogel 2013; Liboiron 2013) to pesticides (Saxton 2015), from flame retardants (Cordner 2016) to formaldehyde (Shapiro 2014), the landscape of toxicant-related science is strewn with examples of intensive data production in a preset direction and an intrinsically unreachable destination, a phenomenon we might call the "data treadmill," as a way of framing our hesitancy, or wariness, towards projects of enumeration ( $c f$ Gould et al. 1996).

\footnotetext{
${ }^{9}$ In its broadest terms, this wariness is evident in the ongoing political theoretical legacy of the Frankfurt School and the contemporary question of instrumentalism; in persistent concerns with technological determinisms; in critical theory in relation to the histories and modalities of scientific knowledge-power. More immediate examples of enumeration, in which numeric verdicts can be foregrounded, also appear in recurrent popular presentations of correlations of intelligence quotients and race; in possible fetishizations of statistical significance across a wide-range of scientific studies; in the monetary valuations of the cost of human and environmental life; in genetic testing producing probabilities of hereditary lines and the onset of future disease; in the question of toxicity and occupational exposure limits; and so on, through to the present discussions of the applications of algorithms and "big data." Throughout, social enumeration is resisted and deployed by political aspirants and activists, of whichever social status, affiliation, or belief.

10 Take ongoing chemical controversies such as those over the plasticizer bisphenol-A or the pesticide Atrazine. Each has produced voluminous research documenting the apparent toxicological hazards of use and exposure. And yet in each case action has largely been limited to the call for more definitive studies. While instances such as these are framed as debates about scientific certainty, they rarely (if ever) afford the opportunity to question the premises that led to the studies in the first place. Why do we need Atrazine? What sorts of worlds does its use make possible, or inhibit (whether discussed, for example, as issues of food sourcing, farm practices, diet, transport and infrastructure, or geographies of production)?
} 
This situation is most visible in the communities where science, exposure, and injustice are most immediately felt. In her work documenting the evolving relationships between the residents of New Sarpy in Southern Louisiana and their industrial nextdoor neighbors, Gwen Ottinger (2013) explores the conflicts that arise when the production, management, and application of data underpin arguments for environmental justice. The community was experiencing a multitude of health and local environmental challenges due to the daily dosings associated with life in close proximity to a petrochemical facility. Residents sought a radical solution to their predicament: they wanted the company that operated the facility to relocate the entire population of their small town, yet the community lacked sufficient public or political power to leverage their neighbor to the negotiating table. Enter the Louisiana Bucket Brigade (LBB), a non-profit situated within the chemical corridor of Louisiana that specializes in the deployment of low-cost, community-operated air monitoring devices. Their eponymous tool, the air sampling bucket, ${ }^{11}$ was lent to the community so that they could create their own arsenal of data to be mobilized in dealings with their industrial neighbors. The implicit assumption of both the LBB and New Sarpy residents was that the data would give the community voice.

The mobilization of data led to an epistemological stalemate as adversarial positions were redrawn to include questions of standards, methods, and significant digits. The community -generated data lacked standing in legal settings that would have mobilized (already difficult to mobilize) state forces. The generation and presentation of data did succeed in mobilizing one previously silent group - the industrial engineers employed by the refinery. Where the LBB and community residents hoped to show systemic harm associated with life along a fenceline, engineers saw structural inefficiencies-leaking pipes, renegade emissions, faulty valves and gauges. The claimed fugitive emissions were likely real, but are due to aberrations fixable at their most proximate source and not a foundational hazard. The engineers appreciated the data. They wanted this data. They would use this data to fix the problem. And, after all, the engineers were the only ones expert enough to translate this data into action-to decide what numbers indicated real versus imagined problems. In this uptake, the data generated by the community simultaneously reconfigured the nature of the problem, the possible solutions, and those with the authority to manage this process.

Following the advice of its engineers, the company did eventually put forth an offer of assistance to the community. It offered to clean up its structural problems, to pursue more

\footnotetext{
11 The bucket is a five-gallon plastic bucket outfitted with a plastic bag liner for sampling, air inlets and outlets drilled into its lid, and a vacuum pump for quickly retrieving real-time air quality samplings. See: http:/ / www.labucketbrigade.org/content/bucket
} 
aggressive monitoring (with the help of the community), and to provide financial assistance to community members looking to improve their own homes in the community. That is, these efforts did not result in a clean separation or a complex troubling of the sustainability of cohabiting with refining, but rather a deepening of the connections between the two neighbors. Those still involved with the community from the LBB advocated for the community members to hold out, to hold their ground, to wait for the relocation. But the residents of New Sarpy had seemingly always known that this fight was far more complicated than any outsiders could know. That the production of data gave the residents a voice, but simultaneously at the cost of reducing their plight to discrete measurable quantities that could never represent the questions of home, life, and family that were always at stake. This use of civic science made the multiply corrosive state of things more bearable rather than substantially questioning the state of things (Fortun and Fortun 2005).

Such historical and contemporary cases and critiques lead us to both wariness and alliance. It is not only those who emphasize the power of technoscientific knowledge who provide reminders of how much social welfare may depend on scientifically minded intervention. Even those who condemn privileging calculative thought themselves concede its importance as one component of a response to the material conditions of living, as part of the work of survival. ${ }^{12}$ We turn now from what provokes hesitation to proposing inroads into a wary alliance between STS and enumerative environmental practices that may help us to better apprehend and differently imagine our world.

\section{Inviting Apprehension}

Drawing from our own individual and collective experiences of STS-in-practice, and those of others who have experimented with and reflected on their own practices, we suggest an approach, or an orientation towards multiple approaches, that we call "inviting apprehension." By this we include any efforts seeking to articulate "the question before the question." By this we refer to the questions often many steps before the burning questions that charge and delimit toxicant-related community science and other contentious environments where science is being brought to bear. Such a retreat of sorts, one that is in the hopes of destabilizing the attritional epistemological struggles that enumerative environmental engagements route into, is not an unfamiliar maneuver. However, the point here is less to emphasize what makes a current

\footnotetext{
12 Bernal might be an example of the former, Horkheimer the latter.
} 
situation knowable or possible, or what historical contingency allowed a given situation to arise, than to find in those prior conditions the possibility of new terms of engagement in the present.

We use the word apprehension because of its multiple valences in the context of protracted and invisible exposures that, as environmental writer Rob Nixon has pointed out, draw "together the domains of perception, emotion, and action" (Nixon 2011: 14). Our invitation to apprehension is an attempt to more self-consciously take stock of, connect, and endorse current methodologies and sets of practices that themselves build on and draw together multiple registers of public collective inquiry and humanistic-troubling of seemingly well established terrain. Inviting modes of thinking through the world that exceed enumerative data will no doubt also induce some unease in scientists and data-driven policy makers, and indeed one of the connotations of inviting apprehension is encouraging a comfort with the discomfort of operating outside of the security of enumerative empiricism and the questions it makes possible and restricts.

Nixon locates the writer-activist as his hopeful figure of toxic apprehension:

Writer-activists can help us apprehend threats imaginatively that remain imperceptible to the senses, either because they are geographically remote, too vast or too minute in scale, or are played out across a time span that exceeds the instance of observation or even the physiological life of the human observer (Nixon 2011: 15).

What Nixon describes as apprehension is the receiving end of charismatic literary representations. Such an understanding of apprehension assumes knowledge of environmental exposure that "exceeds the instance of observation or even physiological life of the human observer" and "requires rendering them apprehensible to the senses through the work of scientific and imaginative testimony" (ibid: 14). We use apprehension, then, to include Nixon's sense of apprehending, holding on at the same time to its standard sense of anxiety. While in agreement with the need for inventive reimagining of environmental conflict, we disagree on where that intervention is best implemented. In our view, it is not that we need better communication, as the power of apprehending exposure is not exclusive to charismatic activists, trailblazing scientists, or clever writers, ${ }^{13}$ but rather is (or ought to be) a precursor to the idea of what needs to be communicated.

To invite apprehension is not to provide counter or alternative facts to established questions, but to reimagine what the appropriate questions (and therefore facts) might be in the

\footnotetext{
13 At a phenomenological level, this capacity for environmental apprehension, for example, is latent in our very ability to be affected by our environment (Shapiro 2015a).
} 
first place. At first glance the move resembles the dramatic analytical U-turn Latour (2004) executed more than a decade ago when he proposed, like a mathematician, that he had been subtracting reality from matters of fact when he should have been adding reality to matters of concern. His analytical apparatus still works, he contends, it was just running backwards. Assemble around our concerns, he urged, rather than unpack the contingencies of facts. Whether we should be subtracting, adding, or multiplying reality, his repentant revisions leave the other variables of his formula, and its axis of creation and destruction, untouched.

Whether endorsed, dismissed, or ignored, the history the Latourian reversal frames much of our discipline and the worlds we investigate. It leaves us asking: What if our goals bridged the investigative with the instigative--seeking to explore the construction of the present moment with methods and tools that help us (and larger publics) to imagine alternative narratives, materialities, and more-than-human relations? What if, instead, the paradigmatic practice of the STS scholar/practitioner included the creation of spaces in which a multiplicity of actors are invited to gather themselves to think through and experiment with the ancillary questions, sensory practices, infrastructures, assumptions of risk, etc. that are bundled up in matters of fact or concern, which are never really that far from each other? To be clear, the move here would not be sorting concerns from facts and choosing to move with one over the other, but collectively leveraging diverse empiricisms to raise, interrogate, and be put into motion by the question(s) before the fact(s) and the question(s) before the concern(s).

This practice is akin to what Noortje Marres has, in the context of the artist collective Hehe's interventions in energy production and urban toxic concerns, called a "deliberate occasion," a forum that "enables all at once research on, the amplification of, and intervention in environments and their attendant issues." Such a happening "seduces actors to stage environmental controversies, rendering them recordable and documentable in a public way" (Marres 2013: 13). The role of the STS practitioner, then, is to create this space where the concerns, rationales, values, and assumptions that lead into an environmental conflict are laid bare, and, through their display, reorganize what futures are possible, desired, causes of suspicion, or already present. ${ }^{14}$

To illustrate invitations to apprehend, we turn to practices that often slide into the broad category of the arts, although the work of community organizing and informal education at times already align with what we are envisioning. Our recourse to creative social practice is likely both

\footnotetext{
14 Like Holmes and Marcus' "para-ethnographic" method that is advanced by "deferring to, absorbing, and being altered by found reflexive subjects," those that invite apprehension view extra-academic collaborators as "epistemic partners" (2008: 84).
} 
active and passive, as the arts are afforded room to act non-instrumentally and "art" often is a residual category applied to public practices that resist easy categorization. Take for example the work of Jenny Price, a PhD'ed historian who practices public environmental humanities work in Los Angeles. Through this work, she came to be known as an "artist," though with no such claim for herself. In a 2014 interview, Price, a co-founder of the LA Urban Rangers, briefly summarizes their practice:

I've written op-eds shaking my fists and being polemical to say this is the problem with privatization of public space. As LA Urban Rangers, we don't do that. We take people down to the Malibu beaches and we perform the ranger character, which is all about public space, we basically perform the beaches as public and we create activities [through which] people can experience the beaches as public (Price and Carruth 2014).

In their collective practice they do not enact enemies against whom to claim victories for the creation of public space but rather perform elements of their desired future in the present, which then provokes stakeholders to ask historical, technical, legal and sociological questions that were previously hidden in plain sight.

An alternate set of practices is at play in the improvisational realist film "WINDJARRAMERU, THE STEALING C*NTS" by the Karrabing Film Collective in Darwin, Australia. The film enacts a form of collective storytelling without scripts that is simultaneously not strictly true and a crystallization of constantly occurring mundane phenomena that hang heavy in the lives of the aboriginal community that wrote, filmed, and starred in WINDJARRAMERU. The collective concisely summarizes the practice as "faking it with the truth." As Karrabing member Elizabeth Povinelli writes, "Perhaps the central purpose of Karrabing's films is to discover what we never knew we knew by hearing what we say in moments of improvisation" (2015). In the film, indigenous actors portray a fictionalized assemblage of all-too-real toxic encounters and end up hiding from the police in territory with known radioactivity produced by illegal mining activities. The hideaways reassure themselves of the protection their exposure provides them, “Don't worry, RJ. They won't come in here. We're safe, too much radiation here; we're safe." And in that moment the actors vocalized a paradox of indigenous sovereignty that they had only tacitly known: that their self-determination was limited to land that settler-colonialists had rendered uninhabitable. In addition to improvising a better understanding of their own condition, the local health department read the film as a hyperreal truth, opening up a line of dialogue that had not been possible to stimulate by traditional means. While the Urban Rangers perform a desired present over its less desirable 
actuality as a way of posing the questions of both why this dream did not become realized and how it can be realized, Karrabing performs their own immiseration as a means of reflexive inquiry that is made public through film and demands apprehension of the numerous material and immaterial infrastructures which maintain that condition.

In the work of both the LA Urban Rangers and the Karrabing Collective, we see the opportunities that performance creates for reframing current debates so as to blur distinctions between categories of health, policy, data, and justice and reorganizing temporal elements of presents, futures, and pasts. In his work with the REACH Ambler ${ }^{15}$ project, a collaboration between researchers at the Chemical Heritage Foundation and the University of Pennsylvania School of Medicine, Jody experimented with ways of theatrically recasting a community's entrenched understanding of the material and cultural legacies of industry in their small Pennsylvania town.

In Ambler, Pennsylvania, the word asbestos carries multiple meanings: the material and industry that built the town; an irrecoverable economy; the "White Hills" that represented the second largest mound of asbestos material in the US; the loss of a public space; a shifting health hazard; and an uncertain future. After the plant's closure in the 1970s, public conversation about asbestos was buried, only re-emerging long enough to sustain moments of renewed interest and reburial. ${ }^{16}$ A 2005 proposal to build a 17-story building on the remaining, un-remediated site exhumed the manifold meanings of asbestos. Residents, new and old, were made to confront the material and cultural legacy of the town simultaneously. Controversy and contestation about the management of the new Superfund site pitted community members against the EPA and against one another.

Transcripts of oral histories with community members and other related historical ephemera became the basis of a newspaper insert, a portable exhibition about the history of the town, and ultimately a series of composed and performed one-act plays (collectively known as,

\footnotetext{
15 Resources for Education and Action for Community Health (REACH) in Ambler is supported by the National Institutes of Health Science Education Partnership Award: Office of the Director, National Institutes of Health, award number R25OD010521-01.

16 A first waste site, known locally as "the White Hills," was added to the EPA's National Priorities List in 1986. The process for remediation involved "capping" the site with fresh soil and grass to keep the material in place.
} 
"The White Mountains"). ${ }^{17}$ In having their perspectives narrated back to them, mediated by curation and interpretation, residents confronted the multiple histories coexisting alongside one another in the community that were shaping how they (individually and collectively) made sense of their present circumstances and imagined what the future of the community could or should be.

There were openings, as well, for unexpected participants to inflect seemingly old questions with new solemnity. The daughter, perhaps ten years old, of a couple recently arrived in the community asked asbestosis and mesothelioma, "can these diseases be cured?" This simple question from a small voice transformed what are typically fact-laden, expert-driven conversations about risk and exposure and probability statistics, like those that Nick rehearsed at the beginning of this article, into a frank and compassionate discussion about the long-term effects of asbestos exposure. Even longstanding activists in the community found an opportunity to briefly be, or approach being, elective community members, part of an audience deliberating over multiple iterations of common experiences. As one attendee noted in a follow-up interview, "I think that the play actually allowed a lot of that surface tension to break [...]. [W]e didn't wear our hats [and so] we could see [each other]." Watching the plays that night helped her to step outside the role she had been playing for the last decade and instead simply watch herself and her community with a sense of clarifying distance. EPA and ATSDR staff, too, were in the audience that night and began to rethink how their technical staff conceptualize and intervene in community toxics issues. ${ }^{18}$

This work evinces the two-way proxy status of toxicity, the community issues for which it can be a cipher and the communal valuations it appears to privilege, which can also encode dilemmas of material toxicity. Asbestos-and what to do about it-had become a proxy for discussions that had no other forum in the community: about community development and

\footnotetext{
17 The oral histories were conducted by Lee Berry, a curator in the Center for Oral History at CHF. The project had a partnership with the Act II Playhouse, located in Ambler, to provide a space for the public performance of the plays. Bill D'Agostino, the director of communications and education at ACT II, facilitated the process of sharing excerpts of the interviews with roughly a dozen local playwrights in Philadelphia. From the one-act plays written, ten were selected for inclusion in the project, and seven were performed at Act II for the local community. Zach Biro conducted follow-up interviews twelve months later. All of these materials are available for use and review at: http: / / reachambler.chemheritage.org.

18 Following the performance and talk-back event, they initiated conversations with the research team to explore how these methods could be brought to other sites in Region 3 and beyond. They've also expressed interest in annual training for their onsite coordinators. "Those coordinators are there to assess and manage a technical problem. They're engineers," suggested one toxicologist who has worked on the site. "But invariably they encounter these same issues, and they have no idea how to handle them."
} 
identity, access to greenspace and recreational space, race relations, and heritage in this demographically shifting town, as well as the health and safety of residents. The specter of toxicity thus motivates participation in public deliberative processes, like those sponsored by the EPA, to achieve extra-toxic goals and justifies non-participation by minority (largely black) community members that suspected toxicity to be another means of maintaining the racialization of space and capital. But the direct relations between the toxic and the social orders to which it relates are not exhausted by even the far-reaching concerns of individual communities.

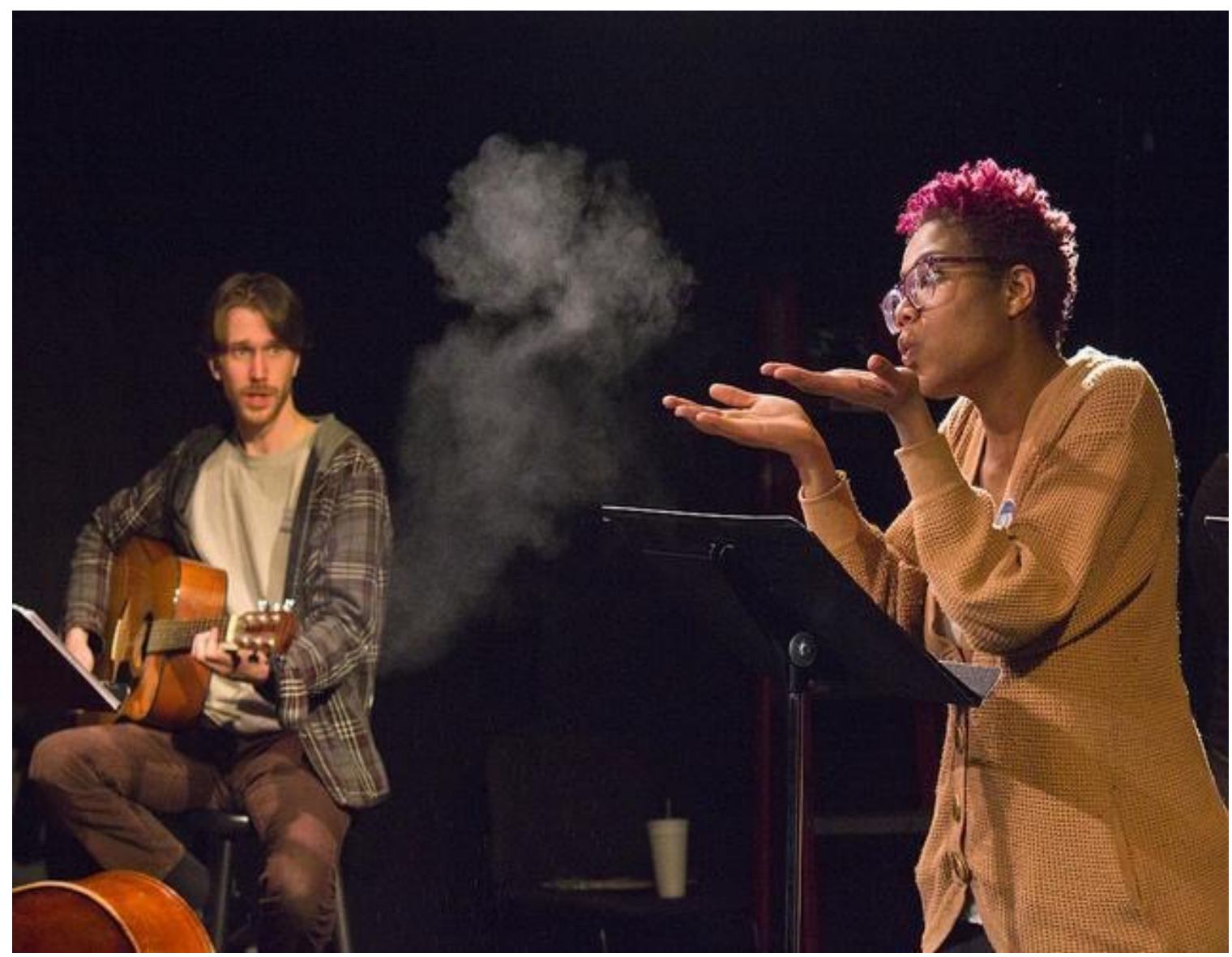

Image 2: Leslie Nevon Holden and Pat Lamborn in The White Mountains, performed at the ACT II Playhouse in Ambler, PA: April, 2015. Photo by Conrad Erb.

In more recent work, Nick follows the proxy of toxicity in a direction that moves from the specific locations of human exposure, like Ambler or the one that opened this essay, to 
geographically larger processes and relations that inform and sustain a multitude of linked exposures. Scholarship traces many genealogies that help us understand why toxic atmospheres, for example, hang heavy when and where they do (industrialism, imperialism, capitalism, etc). Yet, naming contributions to problems does not easily translate to the genesis of cross-cutting alternative configurations. In their work, Nick and collaborators experiment with building an alternative way of conceiving of energy, mobility, and human-environmental relations that does not proceed from problematization or ideological diagnoses. It also does not limit its scope of intervention to sociomaterial processes that one could cleanly identify as having proxy relations with the chemicals he studies. Instead of succumbing to the impasses of adversarial epistemological challenges that attempt to make "necessary evils" less evil, and often end up spinning out on the data treadmill, this process of cultivating alternative desires, dreamworlds, and infrastructures attempts to make toxic infrastructures unnecessary. The approach cultivates abandonment rather than direct dismantlement.

The project, led by artist Tomas Saraceno, is called the Aerocene. The Aerocene is an aspirational epoch that beckons a world in which human circulation is achieved through solar balloon flight, putting to imaginative use the only hydrocarbon-free means of aerospace travel.19 A solar balloon is an envelope that is filled with ambient air, gains altitude with the heat of the sun, and moves with the wind. Conceiving of wind and solar rays as critical infrastructures for the ongoing present demands that our desires for energy and mobility be re-engineered through the planet's shared atmosphere. Working with collaborators at MIT's Department of Earth, Atmospheric and Planetary Sciences to create a float trajectory calculator, a platform that enables one to imagine how to navigate 30 kilometres of different winds at different altitudes, the Aerocene team is not turning its back on science. Rather, the project yokes science to a dreamworld that begins by attuning to and moving with the elemental forces that animate our planet (cf Engelmann \& McCormack In press; Choy 2011). ${ }^{20}$ Advancing the Aerocene, the team avers, bears the capacity to do subjectivity and concept work, cultivating a calculated submission to the environment rather than engineering's current unending quest to interrupt, manipulate,

\footnotetext{
${ }^{19}$ For an initial outline of a terrestrial aspirational era, see Natasha Myers on the "Planthropocene" (2016).

20 This example of the flight trajectory planner underlines the modes of alliance between enumeration and broader apprehension that we are attempting to gesture towards. It is not an attempt to make environmental monitoring data more charismatic or beautiful, even if it achieves that accidently, but puts an immensely large dataset to work towards making an otherwise unimaginable future closer to fruition. While visualizing the harm of toxicants in the air may be another on-ramp to the data treadmill, visualizing an alternative life in the air fundamentally questions the status quo and ideas of what sorts of future merit real consideration. For robust work on toxicant visualizations see the oeuvre of Nerea Calvillo (e.g. http:/ / intheair.es).
} 
overcome the environment. It requires a deferent relation to geophysical forces, surrendering the all-too-human desire for mastery to an outlook in line with what Boyer and Morton (2016) have just begun calling "hypo-subjects," as one potential countervailing force against the hypersubjects that yield the hyper-objects of the Anthropocene.

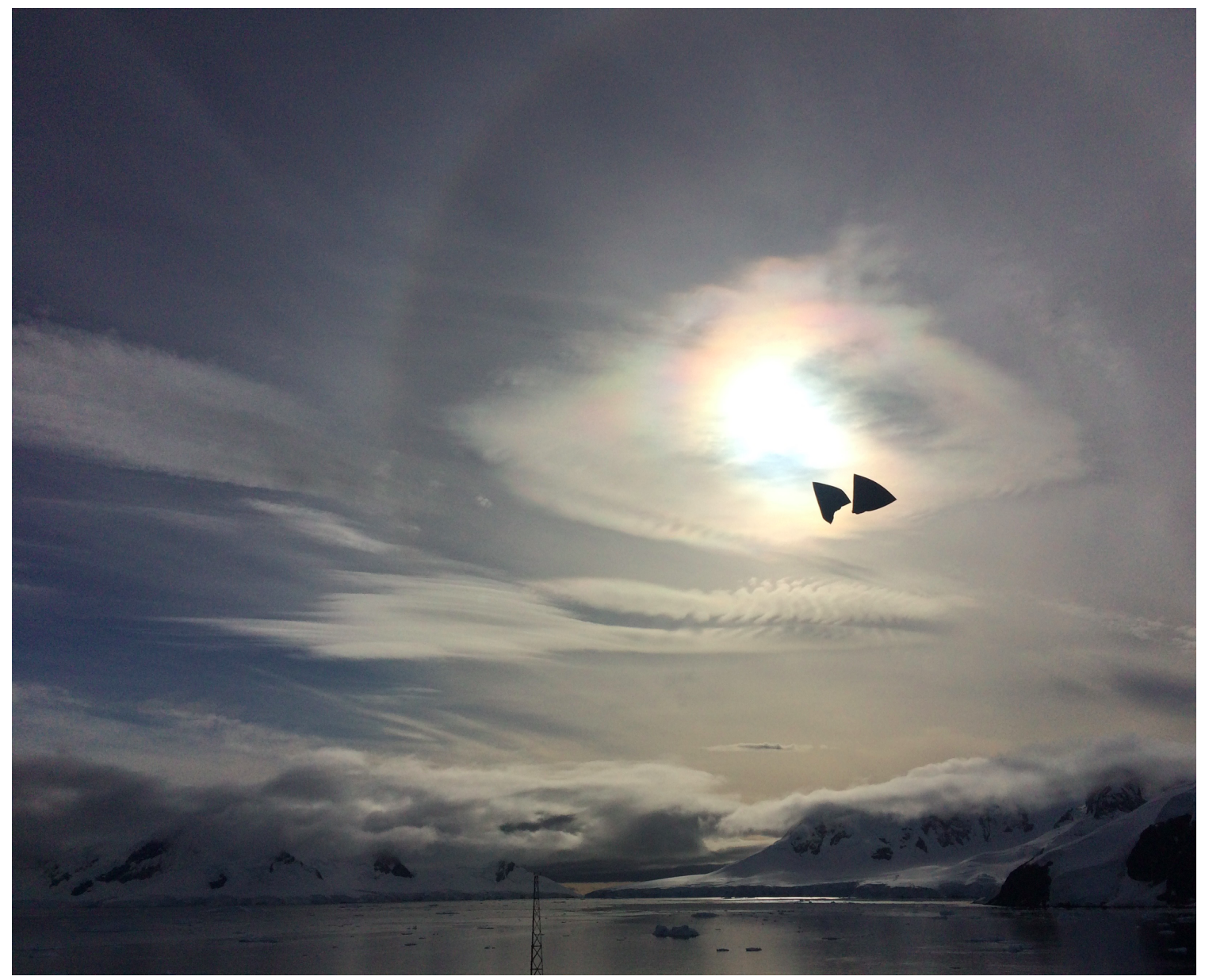

Image 3: Two Aerocene solar sculptures floating above Paradise Bay, Antarctica as a part of the Antarctic Biennale: March 2017. The albedo (reflectivity) of the snow keeps the aerostats afloat even with partial clouds. Photo by Nicholas Shapiro.

This project does not engage with pollution in the terms on which capitalism, governance, and science typically know themselves. It is not chemical-species specific, as a regulation would be. It does not ask for a specific aberrant pollution source to be brought into 
line. It does not make a claim through a process of adjudication that privileges quantified forms of knowledge. Instead, the Aerocene swims upstream from toxicity, beyond its may proxies (corporations, infrastructures, political and economic regimes, etc.), and is an intervention into the very desires that yield a world with cheap fossil fuels, ubiquitous hydrocarbon-derived exposures, and a destabilizing climate (Shapiro 2015b). Like the LA Urban Rangers performing the beaches as public, the Aerocene performs the air as necessary to apprehend and inhabit. It further performs a multi-modal credo for detoxification: to reduce the atmosphere's toxicity we must change our many relations with it, from phenomenological attunement to global engineered systems.

The cases above should not be understood as exemplars of a new method. They are indications from earlier and ongoing efforts informing and concurrent with our search for more capacious modes of apprehension. In the breadth of their concerns, and the different sensibilities with which they are enacted, they already suggest how expansive such apprehending can be. We now find ourselves reflecting on those events and engagements as a means of exploring the possibilities and pitfalls of pursuing a different strategy and approach to contentious questions of health, bodies, infrastructures, energy, and environments.

\section{Imaginative Limits and Plausibilities}

These approaches have also had their share of pitfalls and obstacles. Including, as an example from the Ambler project, community members who felt removed or excluded from the process and an almost ever-present risk of practitioners being enrolled into the charged political factions of the communities where they work. Some approaches might also be viewed or read as illustrations of numbers, and so reinforce rather than transform the enumerative discourses on which they rely, but to which they need not be subordinate. These challenges are not unique to any of these projects, but we do not want to suggest that tumultuous political landscapes simply erode into greener pastures and hand holding if the instruments are left strictly in the lab. Conversely, there should be no need to intimate a self-evident fact, that the most open-sourced, inexpensive, accurate, and easy-to-build sensor will not amount to an environmental justice excalibur or a toxin deterring shield.

Regardless of how successful these experiments were/are/will be, collectively they point to what Fredric Jameson might articulate as the potential utopian dimensions represented or suggested by such works. For Jameson, utopian works reveal the limits of what can be imagined; but, simultaneously, the decline of faith in utopias itself becomes a measure of political 
disenchantment or cynicism (Jameson 2010: 23). Artworks (understood in the broad terms used here) exercise this capacity in ways that may resist such cynicism. Performances can instantiate a space and a moment that stand askew of the spatiotemporal frames they directly thematize. Such an approach suggests that these exercises can stand for what they already are--one of any number of meaningful attempts to reflect creatively, to conceive and convene, free from the obligation to look for their justification in terms of incalculable future consequences or devaluing time frames. And they can at times perhaps rise to what Carrie Lambert-Beatty has referred to as the "art of the plausible," which "works to edge an imagined state of affairs from the merely possible to the brink, at least, of the probable" (Lambert-Beatty 2008: 321). Lambert-Beatty calls attention to the institutional support of practices and products conferred the status of art. The establishment endorsement of art enables and constrains both the plausibility of the political resolutions they enact, as well as the imaginative spaces in which they operate.

In the light of some sweeping, catastrophic scientific prognostications, environmental crises of toxicity, which in our minds also include climate change, appear too dire to leave any possibility of hope for a generative, systemic reconfiguration. But if so, then the utopian impulses at work in attempting to construct different ways of relating to these crises can hardly make those catastrophic futures worse. Thus we might concede with Jameson, in the context of the utopian dimensions of artistic responses to environmental dangers, that "[s]uch a revival of futurity and of the positing of alternate futures is not a political program or even a political practice"; we might also accept with him, however, that "it is hard to see how any durable or effective political action could come into being without it" (Jameson 2010: 43). Waiting for political action based on more enumerated evidence in the absence of imagined possible futures will remain an exercise in frustration and futility.

This article is not about advancing a shift towards art instead of, or in place of, enumeration. Rather, we are suggesting that the humanities and social sciences might play a more critical role in mediating, re-situating, or re-imagining engagement and discussion about societal challenges-even those that seem to pivot on a scientific or technological axes. Artistic methods provide a wide palette of options. But so does history in the form of oral history, or folk history, as well as a growing repertoire of tools in the digital humanities, public history, and what has recently been termed applied history ( $c f$ Rose et al. 2012). 


\section{A Wary Alliance}

Why a wary alliance between enumerative environmental practices and science studies? STS is a political science insofar as it does its best to embrace rather than contest the inherent political nature of its work, its activity, and indeed its very existence. This is not meant to imply a specific or monolithic political action or agenda; nor does it hew to a specific or unified mode or method. In this vein, the turn within the field towards participating through and with new scientific and technological apparatuses is both an obvious outcome and a potentially potent one. This reproducing and remaking of the more familiar scientific modes of interaction/intervention does not negate the decades of research that have sought to uncover, disentangle, and otherwise explain the potent political power science possesses in our society. Navigating this past and present of power politics in and with science must continue to be the burden of the engaged science studies practitioner. But in the cases of work with communities, the sites for most of these interventions, the most dangerous traps lie not in weaknesses of science, but in its power to so easily, so quickly, become the dominant discourse of a space/issue. In these communities, discourses with the mantle of science are granted great power, though not unchallenged, to quash discussion and debate on or with other (moral, social, political, etc.) topics. We've seen this dominance lead to reifying the intrinsic answerability of enumerable questions, and therefore the denial of the data treadmill, as well as a strict demarcation of what paths to an otherwise are unrealistic and what compromised worlds are inevitable.

The participation of science studies scholars in closing those other discursive avenues, even if unwittingly, could mean relegating some voices to the sideline while simultaneously reifying social structures of expertise that assume the apolitical nature of science, define how activism and participation must be manifested, and the form by which grievances can be aired. For these reasons we feel compelled, in the context of this thematic collection, to think through: what modes of expertise, authority, and power can't be shaken loose within the practice of civic science?

Our point is not, of course, that community science should not be practiced, but rather to endorse a multiplicity of practices in the critique and use of science, whether by attempts to remake science through bottom-up civic action (as many within this collection are working towards) and/or by promoting, instigating, and eliciting apprehension without stipulating a formula for how that will happen. The social and political power of science is both the reason why we should, perhaps even must, employ science, but it is also why we must remain wary and perhaps even at times slow our recourse to civic science to allow for other forms of imagination and engagement to take root or even take the lead before the pursuit of scientific enumeration. 
As Cedric Price joked in 1966, “Technology is the answer but what was the question?" The allure of technology often enacts the question to which it responds. So our hope is to make room with ecologies of instruments (Wylie et al., this thematic collection) for diverse practices that prime apprehension, beckon further thought, illuminate radical alterities, or articulate the histories (supply chains, infrastructures, consumer demands, etc.) that lead to concerns of toxicity, while still leaving multiple meanings to exist simultaneously.

The inherent inability of science, conventionally understood, to provide political solutions is something that exists at the macro and the micro levels, both global and local. We should be careful not to assume that providing new data will provide new political answers (or even the resolve to seek new political answers). To the extent that new questions, new data, and new instruments can participate within this ecology of practices of understanding and experiencing environments, helping to invite apprehension that avoids facile or even false solutions, we have an obligation to use, remake, and leverage the power of science for these purposes. If we were to return to Joe in his trailer, our hope by this point in the article is that the reader would want to suggest changing the terms of the conversation (even while including the measurement) and perhaps deciding together with Joe what might amount to the plausible, the imaginable, and the livable. We hope these provocations help to open up seemingly intractable issues and inevitable toxicities, inviting those with the highest stakes to help realize the unlikely but very possible futures that route us away from such morasses as those faced by Joe and others who may take his place. And in so doing, we, however minimally, work towards a form of participation in our democratic systems that does not require a dataset for entry into the dialogue.

\section{Author Biography}

Nicholas Shapiro is the Matter, Materials and Culture Fellow at the Chemical Heritage Foundation, the Open Air Fellow at Public Lab, and a Visiting Research Professor at Drexel University.

\section{Author Biography}

Nasser Zakariya is an assistant professor in the Department of Rhetoric at the University of California, Berkeley. 


\section{Author Biography}

Jody A. Roberts is the Director of the Institute for Research at the Chemical Heritage Foundation.

\section{Acknowledgements}

We would like to thank the anonymous reviewer, Daniel Lee Kleinman, and Katie Vann for their

generous insights, in addition to those by Max Liboiron, Sara Wylie, Ana Rosen Vollmar, the Center for the Study of Science, Technology, Medicine and Society at University of California, Berkeley, fellows and staff in the Institute for Research at CHF, Christy Schneider, and several close reads by Wyatt Galusky.

\section{References}

Bernal, J. D. 1945. “Transformation in Science.” The Scientific Monthly 61: 474-76.

Boudia, Soraya, and Nathalie Jas. 2014. Powerless Science?: Science and Politics in a Toxic World. New York: Berghahn Books.

Boyer, Dominic, and Timothy Morton. 2016. "Hyposubjects - Cultural Anthropology." Cultural Anthropology. https: / / culanth.org/ fieldsights / 798-hyposubjects.

Brody, Julia, Sarah C Dunagan, Rachel Morello-Frosch, Phil Brown, Sharyle Patton, and Ruthann A Rudel. 2014. "Reporting Individual Results for Biomonitoring and Environmental Exposures: Lessons Learned from Environmental Communication Case Studies." Environmental Health 13, no. 1:40. doi:10.1186/1476-069X-13-40.

Carruth, Allison, and Jenny Price. 2014. "The Power of Play in Urban Environmentalism: Interview with Jenny Price." Resilience: A Journal of the Environmental Humanities 1, No. 1 https: / / muse.jhu.edu/article/565576.

Choy, Timothy K. 2011. Ecologies of Comparison: An Ethnography of Endangerment in Hong Kong. Durham: Duke University Press.

Cohn, Bernard S. Colonialism and Its Forms of Knowledge. Princeton, N.J: Princeton University Press, 1996.

Cordner, Alissa. 2016. Toxic Safety: Flame Retardants, Chemical Controversies, and Environmental Health. Columbia University Press.

Engelmann, Sasha, and Derek P. McCormack. In Press. “Elemental Aesthetics: On Artistic Experiments with Solar Energy." Annals of the Association of American Geographers. 
Fortun, Kim, and Mike Fortun. 2005. "Scientific Imaginaries and Ethical Plateaus in Contemporary U.S. Toxicology." American Anthropologist 107, No. 1: 43-54. doi:10.1525/aa. 2005.107.1.043.

Foucault, Michel. 2009. Security, Territory, Population: Lectures at the College de France 1977--1978. 1st ed. Picador.

—. 2003. "Society Must Be Defended": Lectures at the College de France, 1975-1976. New York: Picador.

Gehrke, Gretchen, and Nicholas Shapiro. 2015. "Formaldehyde Measurement: Testing Public Lab's Kit with DOH's Equipment." https://publiclab.org/notes/gretchengehrke/ 10-07-2015/ formaldehyde-measurement-testing-public-lab-s-kit-with-doh-s-equipment.

Gould, Kenneth A., Allan Schnaiberg, and Adam S. Weinberg. 1996. Local Environmental Struggles: Citizen Activism in the Treadmill of Production. Cambridge: Cambridge University Press.

Hacking, Ian. 1990. The Taming of Chance. 1 edition. Cambridge England; New York: Cambridge University Press.

Hale, Charles R. 2006. "Activist Research v. Cultural Critique: Indigenous Land Rights and the Contradictions of Politically Engaged Anthropology." Cultural Anthropology 21, no. 1: 96-120. doi:10.1525/can.2006.21.1.96.

Horkheimer, Max. 1972. "The Latest Attack against Metaphysics." In Critical Theory: Selected Essays. Vol. 1. A\&C Black.

Jameson, Frederic. 2010. “Utopia as Method, or the Uses of the Future." In Utopia/Dystopia: Conditions of Historical Possibility, edited by Michael D. Gordin, Helen Tilley, and Gyan Prakash, 21-44. Princeton University Press.

Kinchy, Abby, Kirk Jalbert, and Jessica Lyons. 2014. "What Is Volunteer Water Monitoring Good for? Fracking and the Plural Logics of Participatory Science." In Fields of Knowledge: Science, Politics and Publics in the Neoliberal Age, edited by Scott Frickel and David J. Hess, 27:259-89. Emerald Group Publishing Limited.

Lambert Beatty, Carrie. 2008. "Twelve Miles: Boundaries of the New Art/Activism." Signs: Journal of Women in Culture and Society 33, no. 2:309-27. doi:10.1086/521179.

Latour, Bruno. 2004. "Why Has Critique Run out of Steam? From Matters of Fact to Matters of Concern." Critical Inquiry 30, No. 2:225-48. doi:10.1086/421123.

Liboiron, Max. 2013. “Plasticizers: A Twenty-First Century Miasma." In Accumulation: The Material Politics of Plastics, edited by Mike Michael, Gay Hawkins, and Jennifer Gabrys, 22-44. Routledge. 
Marres, Noortje. 2013. "Who Is Afraid of the Green Cloud? On the Environmental Rendering of Controversy." CSISP Working Paper Nr. 2, Centre for the Study of Invention \& Social Process, No. 2:1-25.

Mitchell, Timothy. 2002. Rule of Experts: Egypt, Techno-Politics, Modernity. Berkeley: University of California Press.

Myers, Natasha. 2016. "Photosynthesis." Theorizing the Contemporary, Cultural Anthropology Website. https: / / culanth.org/ fieldsights / 790-photosynthesis.

Nixon, Rob. 2011. Slow Violence and the Environmentalism of the Poor. Cambridge: Harvard University Press.

Ottinger, Gwen. 2013. Refining Expertise: How Responsible Engineers Subvert Environmental Justice Challenges. New York: NYU Press.

Paul, Diane B. 1998. The Politics of Heredity: Essays on Eugenics, Biomedicine, and the Nature-Nurture Debate. N edition. Albany: State University of New York Press.

Poovey, Mary. 1998. A History of the Modern Fact: Problems of Knowledge in the Sciences of Wealth and Society. 1 edition. Chicago: University Of Chicago Press.

Porter, Theodore M. 1996. Trust in Numbers. Reprint edition. Princeton, N.J.: Princeton University Press.

Povinelli, Elizabeth A. 2015. “Windjarrameru, The Stealing C*nts." E-Flux. http:// supercommunity.e-flux.com/texts / windjarrameru-the-stealing-c-nts / .

Roberts, Jody. 2014. "Unruly Technologies and Fractured Oversight: Toward a Model for Chemical Control for the Twenty-First Century." In Powerless Science?: Science and Politics in a Toxic World, edited by Soraya Boudia and Nathalie Jas, 1 edition. New York: Berghahn Books.

Roberts, Jody A. 2010. "Reflections of an Unrepentant Plastiphobe: Plasticity and the STS Life." Science as Culture 19, no. 1: 101-20. doi:10.1080/09505430903557916.

Rose, Deborah Bird, Thom van Dooren, Matthew Chrulew, Stuart Cooke, Matthew Kearnes, and Emily O'Gorman. 2-12. "Thinking Through the Environment, Unsettling the Humanities." Environmental Humanities 1, no. 1:1-5. doi:10.1215/22011919-3609940.

Scott, James C. 1999. Seeing like a State: How Certain Schemes to Improve the Human Condition Have Failed. New Haven: Yale University Press.

Shapiro, Nicholas. 2014. “Un-Knowing Exposure: Toxic Emergency Housing, Stratigic Inconclusivity and Governance in the US Gulf South." In Knowledge, Technology and Law, edited by Emilie Cloatre and Pickersgill Martyn, 189-205. New York; London: Routledge. 
.2015a"Attuning to the Chemosphere: Domestic Formaldehyde, Bodily Reasoning, and the Chemical Sublime." Cultural Anthropology 30, no. 3:368-93. doi:10.14506/ ca30.3.02.

_. 2015b. "Alter-Engineered Worlds." Aerocene COP21 Catalog.

Stocking, George W. 1994. “The Turn-of-the-Century Concept of Race.” Modernism/Modernity 1, no. 1: 4-16. doi:10.1353/mod.1994.0015.

Vogel, Sarah Ann. 2013Is It Safe?: BPA and the Struggle to Define the Safety of Chemicals. Oakland: University of California Press.

Wylie, Sara Ann, Kirk Jalbert, Shannon Dosemagen, and Matt Ratto. 2014. "Institutions for Civic Technoscience: How Critical Making Is Transforming Environmental Research." The Information Society 30, no. 2:116-26. doi:10.1080/01972243.2014.875783. 